\title{
Heterosynaptic Long-Term Potentiation at GABAergic Synapses of Spinal Lamina I Neurons
}

\author{
Henning Fenselau, Bernhard Heinke, and Jürgen Sandkühler \\ Department of Neurophysiology, Center for Brain Research, Medical University of Vienna, 1090 Vienna, Austria
}

Neurons in spinal dorsal horn lamina I play a pivotal role for nociception that critically depends on a proper balance between excitatory and inhibitory inputs. Any modification in synaptic strength may challenge this delicate balance. Long-term potentiation (LTP) at glutamatergic synapses between nociceptive C-fibers and lamina I neurons is an intensively studied cellular model of pain amplification. In contrast, nothing is presently known about long-term changes of synaptic strength at inhibitory synapses in the spinal dorsal horn. Using a spinal cord-dorsal root slice preparation from rats, we show that conditioning stimulation of primary afferent fibers with a stimulating protocol that induces LTP at C-fiber synapses also triggered LTP at GABAergic synapses $\left(\mathrm{LTP}_{\mathrm{GABA}}\right)$. This LTP $_{\text {GABA }}$ was heterosynaptic in nature and was mediated by activation of group I metabotropic glutamate receptors. Opening of ionotropic glutamate receptor channels of the AMPA/KA or NMDA subtype was not required for $\mathrm{LTP}_{\mathrm{GABA}}$. Paired-pulse ratio, coefficient of variation, and miniature IPSCs analysis revealed that $\mathrm{LTP}_{\mathrm{GABA}}$ was expressed presynaptically. Nitric oxide as a retrograde messenger signal mediated this increase of GABA release at spinal inhibitory synapses. This novel form of synaptic plasticity in spinal nociceptive circuits may be an essential mechanism to maintain the relative balance between excitation and inhibition and to improve the signal-to-noise ratio in nociceptive pathways.

\section{Introduction}

Neurons in lamina I of the spinal dorsal horn are critically involved in the integration of nociceptive information that is relayed to the brain (Todd, 2010). Lamina I neurons receive monosynaptic glutamatergic input from $\mathrm{A} \delta$ - and $\mathrm{C}$-fiber nociceptors and are under permanent GABAergic control by interneurons (Yoshimura and Nishi, 1995; Seagrove et al., 2004; Dahlhaus et al., 2005).

An appropriate GABAergic inhibition in superficial spinal dorsal horn is fundamental for normal nociception, as intrathecal application of $\mathrm{GABA}_{\mathrm{A}}$ receptor antagonists induces signs of severe pain in animals (Yaksh, 1989; Ishikawa et al., 2000). Lowthreshold sensory input to lamina I neurons, which is absent under normal conditions, is unmasked upon blockade of GABAergic inhibition (Baba et al., 2003; Torsney and MacDermott, 2006; Schoffnegger et al., 2008). Consistently, bicuculline enhances low threshold-mediated action potential firing of lamina I neurons in vivo (Seagrove et al., 2004). In addition, changes in spinal GABAergic inhibition have been shown to play important roles in the manifestation of neuropathic and inflammatory pain states (Moore et al., 2002; Coull et al., 2003; Poisbeau et al., 2005). Conversely, thermal hyperalgesia and tactile allodynia in

\footnotetext{
Received June 16, 2011; revised Oct. 4, 2011; accepted 0ct. 9, 2011.

Author contributions:H.F., B.H., and J.S. designed research; H.F. performed research;H.F. and B.H. analyzed data; H.F. and J.S. wrote the paper.

This project was supported by the Austrian Science Fund (FWF Grant P19367) and by the Anniversary Fund (Jubilaeumsfond) of the Austrian National Bank to J.S.

The authors declare no competing financial interests.

Correspondence should be addressed to Dr. Jürgen Sandkühler, Department of Neurophysiology, Center for Brain Research, Medical University Vienna, 1090 Vienna, Austria. E-mail: juergen.sandkuehler@meduniwien.ac.at. DOI:10.1523/JNEUROSCI.3076-11.2011

Copyright $\odot 2011$ the authors $\quad 0270-6474 / 11 / 3117383-09 \$ 15.00 / 0$
}

neuropathic animals can be reversed by GABA receptor agonist applied intrathecally (Malan et al., 2002).

Activity-dependent forms of plasticity at spinal excitatory synapses are believed to underlie diverse forms of pain amplification (Sandkühler, 2009). Long-term potentiation (LTP) at glutamatergic synapses between nociceptive nerve fibers and spinal dorsal horn neurons has been studied intensively (Randic et al., 1993; Ikeda et al., 2003, 2006; Drdla et al., 2009). Perceptual correlates of LTP in nociceptive pathways have been demonstrated in humans (Klein et al., 2004), and behavioral correlates exist in animals (Zhang et al., 2005). In striking contrast, nothing is presently known about long-term changes of synaptic efficacy at spinal inhibitory synapses. Long-term changes of GABAergic inhibition of spinal lamina I neurons could significantly shift the balance between inhibitory and excitatory drive and may also have an impact on the induction of plasticity at excitatory synapses, as described for other brain regions (Chen et al., 2010).

Here we identified a novel form of heterosynaptic LTP at GABAergic synapses on spinal lamina I neurons that is triggered by activity in primary afferent nerve fibers. We found that convergent monosynaptic $\mathrm{A} \delta$ - or $\mathrm{C}$-fiber afferent input was required for the induction of heterosynaptic LTP at GABAergic terminals that was mediated by group I metabotropic glutamate receptors (mGluRs) and nitric oxide (NO) as a retrograde messenger.

\section{Materials and Methods}

Spinal cord slice preparation. Young male Sprague Dawley rats (aged 25-35 d) were deeply anesthetized with isoflurane and killed by decapitation. A laminectomy was performed and the spinal cord was quickly removed into ice-cold incubation solution consisting of (in $\mathrm{mM}$ ): 95 $\mathrm{NaCl}, 1.8 \mathrm{KCl}, 1.2 \mathrm{KH}_{2} \mathrm{PO}_{4}, 0.5 \mathrm{CaCl}_{2}, 7 \mathrm{MgSO}_{4}, 26 \mathrm{NaHCO}_{3}, 15$ glucose, and 50 sucrose, oxygenated with $95 \% \mathrm{O}_{2} / 5 \% \mathrm{CO}_{2}, \mathrm{pH} 7.4$, mea- 
sured osmolarity $310-320 \mathrm{mOsm} \cdot 1^{-1}$. The dura mater and the ventral roots were removed. Parasagittal slices with attached dorsal roots (10-15 mm long) were cut at 400-600 $\mu \mathrm{m}$ thickness using a vibrating microslicer (DTK-1000, Dosaka) and kept in the incubation solution at $33^{\circ} \mathrm{C}$ for at least $30 \mathrm{~min}$. After this, the slices were stored in the same solution at room temperature $\left(20-24^{\circ} \mathrm{C}\right)$.

All experiments were in accordance with directive 2010/63/EU of the European Parliament and the council of the European Union.

Whole-cell patch-clamp recordings from spinal lamina I neurons. A single slice was placed in the recording chamber where it was continuously superfused at a rate of $3-4 \mathrm{ml} \cdot \mathrm{min}^{-1}$ with oxygenated extracellular solution, which was identical to the incubation solution except for the following (in mM): $127 \mathrm{NaCl}, 24 \mathrm{CaCl}_{2}$, $1.3 \mathrm{MgSO}_{4}, 0$ sucrose. Recordings were made at $32 \pm 1^{\circ} \mathrm{C}$. Neurons of the dorsal horn were visualized with an Olympus BX 51WI (Olympus Optical) microscope equipped with Dodt infrared optics (Dodt et al., 1999). Only neurons at a distance of $<20 \mu \mathrm{m}$ from the dorsal white/gray matter border were considered as being lamina I neurons and thus used for experiments.

GABAergic IPSCs were recorded at a holding potential of $0 \mathrm{mV}$ using an Axopatch 200B patch-clamp amplifier and the pCLAMP 9 software package (both Molecular Devices). No correction for the liquid junction potential was made. Signals were low-pass filtered at $2-10 \mathrm{kHz}$, sampled at $10-20 \mathrm{kHz}$, and analyzed offline using pCLAMP 9. Patch pipettes (2-5 $\mathrm{M} \Omega$ ) from borosilicate glass were filled with a cesium-based intracellular solution composed of the following (in mM): $120 \mathrm{CsMeSO}_{3}, 20$ TEA-Cl, $2 \mathrm{MgCl}_{2}, 2 \mathrm{Na}_{2}$ ATP, 10 EGTA, 0.5 NaGTP, 10 HEPES, pH 7.28, with CsOH; measured osmolarity was $300 \mathrm{mOsm} \cdot 1^{-1}$.

IPSCs were pharmacologically isolated by bath application of antagonists to glycinergic and glutamatergic ionotropic transmission $[1 \mu \mathrm{M}$ strychnine, $50 \mu \mathrm{M} \mathrm{D}-(-)-2$-amino-5-phosphonopentanoic acid (D-AP5), and $10 \mu \mathrm{M}$ 6-cyano7-nitroquinoxaline-2,3-dione (CNQX)]. A patch pipette filled with extracellular solution was placed within $20-40 \mu \mathrm{m}$ from the cell body of the patched neuron, and monosynaptic IPSCs were evoked by single monopolar square pulse stimulation. Test pulses of $0.1 \mathrm{~ms}$ duration were given at intervals of $15 \mathrm{~s}$. At the end of all experiments, bicuculline $(10 \mu \mathrm{M})$ was bath applied and completely blocked IPSCs, confirming that they were mediated by $\mathrm{GABA}_{\mathrm{A}}$ receptors.

Conditioning high-frequency stimulation (HFS, 100 pulses at $100 \mathrm{~Hz}$ repeated 3 times at $10 \mathrm{~s}$ intervals) was applied to attached dorsal roots at C-fiber intensity $(5 \mathrm{~mA})$ and $0.1 \mathrm{~ms}$ pulse width via a suction electrode with an isolated current stimulator (A360, World Precision Instruments). When HFS was applied, neurons were kept in voltage-clamp mode at $0 \mathrm{mV}$. To test whether the neurons received monosynaptic input from the attached dorsal root, all drugs were washed out at the end of the experiment. The neurons were then voltage clamped to a holding potential of $-70 \mathrm{mV}$ and EPSCs were evoked by stimulating the attached dorsal root
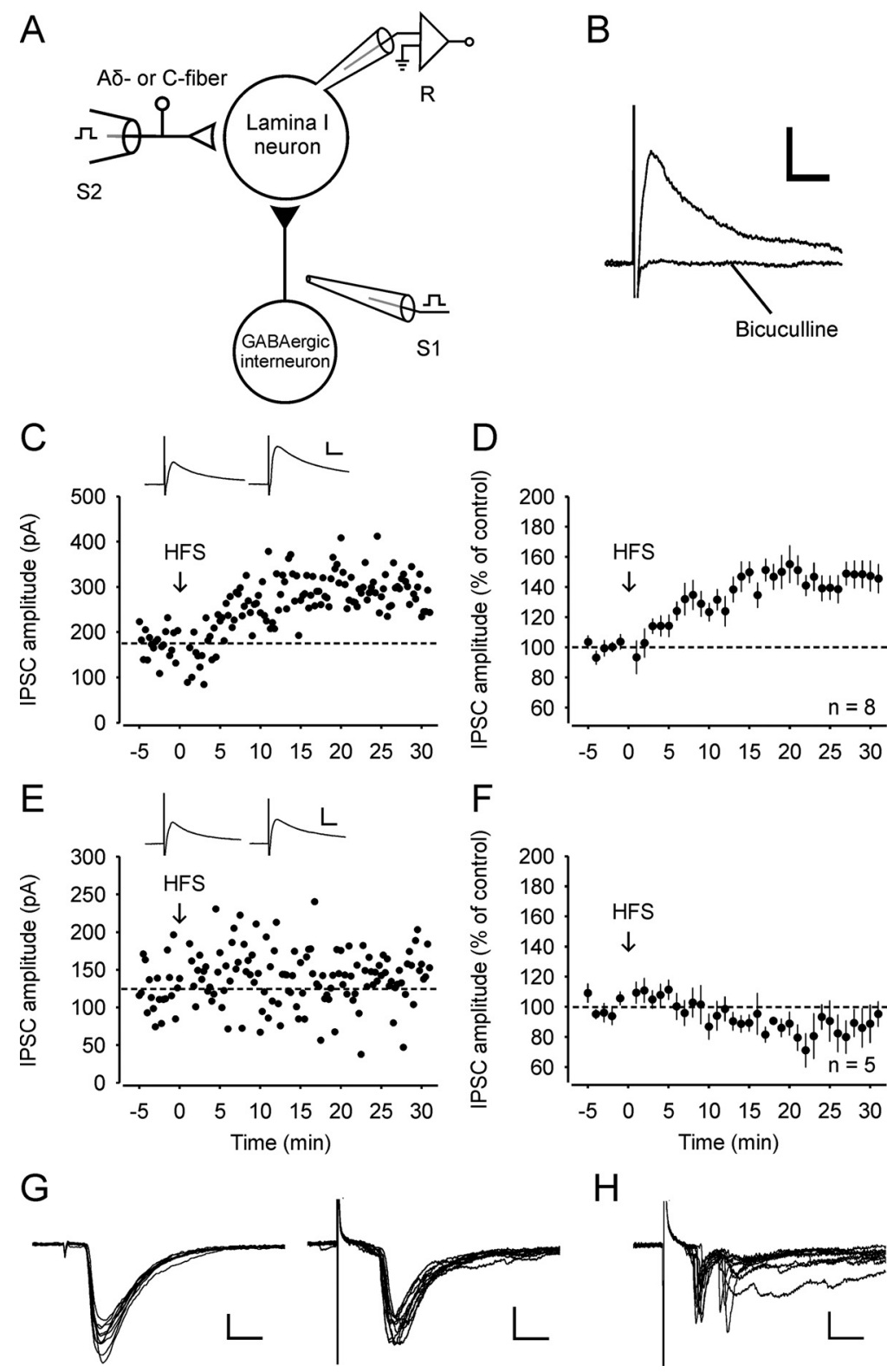

Figure 1. LTP at GABAergic synapses with spinal lamina I neurons that receive monosynaptic glutamatergic input from primary afferent $A \delta$-fibers or $C$-fibers. A, Schematic illustration of stimulating and recording electrodes. Monosynaptic IPSCs were evoked by a focal stimulation electrode (S1) placed medially to the recorded lamina I neuron (R). An attached dorsal root was stimulated via a suction electrode (S2) that was used for conditioning stimulation and for the identification of glutamatergic input. Black triangle, Inhibitory synapse; open triangle, excitatory synapse. $\boldsymbol{B}$, Typical example of a monosynaptic IPSC recorded in the presence of CNQX, D-AP5, and strychnine. The IPSC was abolished by bicuculline. $C$, Representative example of $\mathrm{LTP}_{\mathrm{GABA}}$ in a neuron that received monosynaptic afferent input from A $\delta$-fibers. HFS was applied at the time point zero (arrow). CNQX, D-AP5, and strychnine were present in the bath solution throughout the recording period. Monosynaptic $A \delta$-fiber input was verified at the end of the experiment. The dotted lines in this and in all other graphs indicate the mean IPSC amplitudes during the control period. Inset: Average of 20 IPSCS $0-5$ min before and $25-30$ min after conditioning stimulation. D, Average time course of IPSCs recorded from all eight spinal lamina I neurons that received monosynaptic $A \delta$-fiber or C-fiber input. Each point was averaged from four IPSCS and normalized to the control period of 20 IPSCs. E, Example of an experiment where HFS did not affect IPSC amplitudes. The neuron received polysynaptic but no monosynaptic input from C-fibers. $\boldsymbol{F}$, Time course of IPSCs from five neurons that did not receive any monosynaptic input. $G$, Examples of monosynaptic A $\delta$-fiber (elicited at a frequency of $10 \mathrm{~Hz}$ and stimulation intensity of $120 \mu \mathrm{A}$; left) and monosynaptic C-fiber input (evoked at $1 \mathrm{~Hz}$ and $3.2 \mathrm{~mA}$; right). $\boldsymbol{H}$, Example of polysynaptic input from dorsal root afferents (stimulated at $1 \mathrm{~Hz}$ and $5 \mathrm{~mA}$ ). In $\mathbf{G}$ and $\boldsymbol{H}$ glutamatergic EPSCs were evoked by stimulation of attached dorsal roots at a holding potential of $-70 \mathrm{mV}$ at the end of the experiments. Ten EPSCs are superimposed in each example. Calibration: $10 \mathrm{~ms}, 100 \mathrm{pA}$ ( $\boldsymbol{B}, \boldsymbol{C}$, and $\boldsymbol{E}) ; 2.5 \mathrm{~ms}, 100 \mathrm{pA}$ (left) and $10 \mathrm{~ms}, 100 \mathrm{pA}$ (right) (G); $10 \mathrm{~ms}, 50 \mathrm{pA}(\boldsymbol{H})$.

via the suction electrode. Evoked EPSCs were classified as A $\delta$-fiber-evoked when the calculated conduction velocity was above $1.5 \mathrm{~m} \cdot \mathrm{s}^{-1}$ and as $\mathrm{C}$-fiber-evoked when the conduction velocity was below $0.5 \mathrm{~m} \cdot \mathrm{s}^{-1}$. Monosynaptic input was identified by the absence of failures in response to 10 

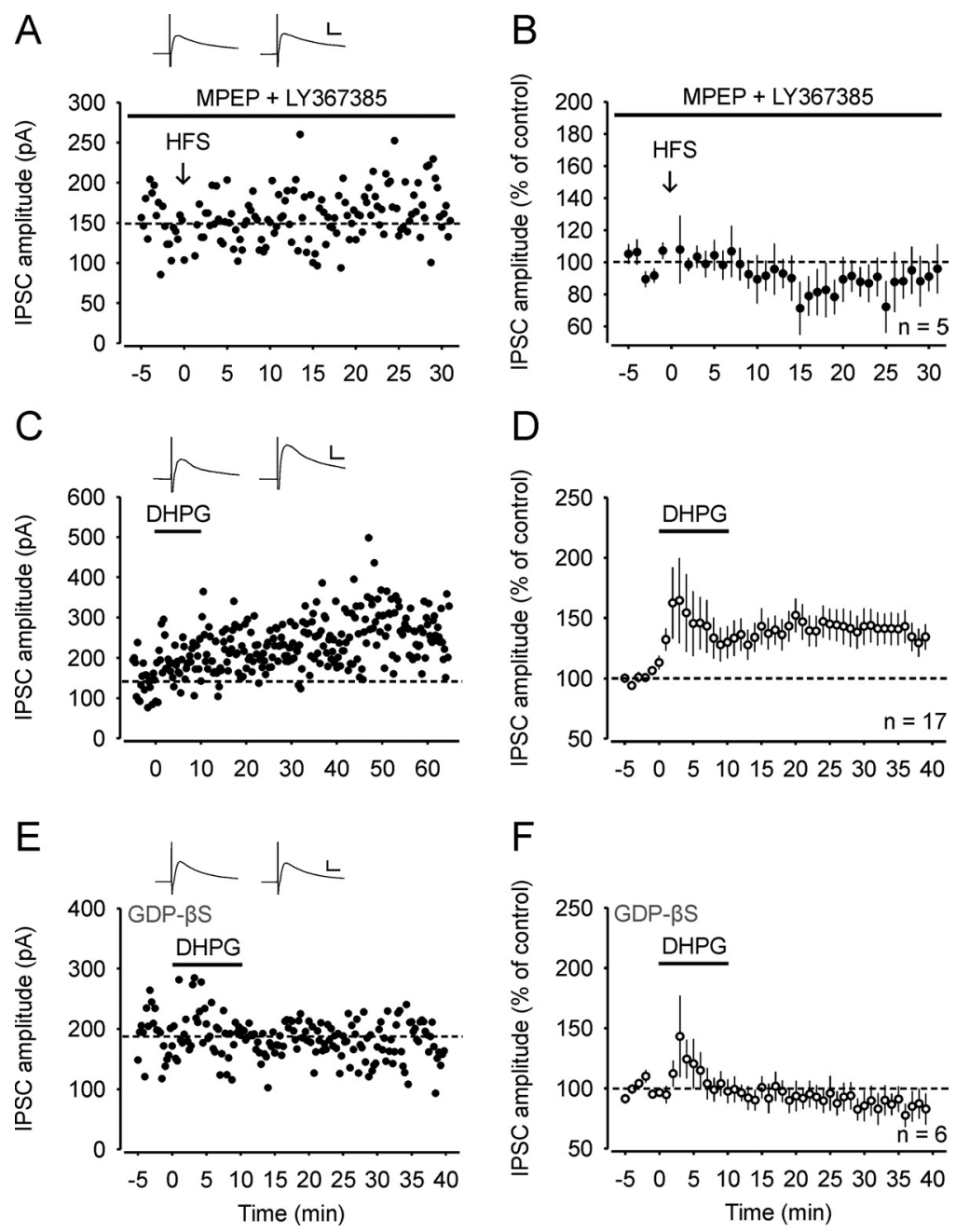

Figure 2. $\mathrm{LTP}_{\mathrm{GABA}}$ is mediated by group I metabotropic glutamate receptors. $\boldsymbol{A}$, Example of an experiment where HFS was delivered in the presence of mGluR1 and mGluR5 antagonists MPEP (30 $\mu \mathrm{M})$ and LY367385 (100 $\mu \mathrm{M})$, respectively. The neuron received monosynaptic C-fiber input. $\boldsymbol{B}$, Average of five experiments where group I mGluR antagonists were applied during HFS. All neurons received either monosynaptic $A \delta$-fiber or $C$-fiber input. $C$, Example of an experiment where the specific group I $m G$ luR agonist DHPG $(50 \mu \mathrm{M})$ was applied to the bath solution and potentiated the IPSC amplitudes. D, Average time course of IPSCs recorded from 17 spinal lamina I neurons where DHPG was bath-applied. $\boldsymbol{E}$, Example of an experiment where DHPG was bath applied when GDP- $\beta S(0.5 \mathrm{~mm})$ was included in the pipette solution to inhibit postsynaptic G-proteins. $\boldsymbol{F}$, Average of six experiments where GDP- $\beta$ S, included in the pipette solution, abolished DHPG-induced LTP ${ }_{G A B A}$. Insets, Average of 20 IPSCS $0-5$ min before and 25-30 min after conditioning stimulation ( $A$ ) or 25-30 min after wash-out of DHPG ( $C$ and $E$ ). Calibration: $10 \mathrm{~ms}$, $100 \mathrm{pA}$.

stimuli at $10 \mathrm{~Hz}$ (A $\delta$-fiber input) or $1 \mathrm{~Hz}$ (for C-fiber input) stimulation of dorsal roots and a jitter in response latencies $<10 \%$ of the response delay. In all experiments only one neuron per spinal cord slice was used.

GABAergic miniature IPSCs (mIPSCs) were recorded in presence of lidocaine $(2 \mathrm{~mm})$ to block action potential-dependent effects. Lidocaine applied to the bath solution completely blocked action potential firing of spinal dorsal horn neurons induced by postsynaptic depolarization and monosynaptic EPSCs evoked by stimulation of attached dorsal roots within $5 \mathrm{~min}$. Monosynaptic EPSCs completely recovered after wash-out of lidocaine for $15 \mathrm{~min}(n=3$; data not shown).

Series resistance was monitored throughout the experiment. Neurons were discarded if the series resistance changed by $>10 \%$ during the experiment.

Analysis. IPSCs were analyzed offline using Clampfit 10. Synaptic strength was quantified by measuring the peak amplitude of monosynaptic IPSCs. The mean amplitude of 20 IPSCs evoked by test stimuli served as a control. Two pulses were given with an interstimulus interval of $50 \mathrm{~ms}$. The paired-pulse ratio (PPR) was determined by dividing the amplitude of the second IPSC by the amplitude of the first IPSC and averaged over $5 \mathrm{~min}$ epochs of 20 IPSCs. The squared coefficient of variation
$\mathrm{CV}^{2}\left(\mathrm{CV}^{-2}=\right.$ mean $^{2} /$ variance $)$ was calculated for 5 min epochs of 20 IPSCs and normalized to the control period.

Means of IPSC amplitudes, PPR, and $\mathrm{CV}^{-2}$ are reported for $5 \mathrm{~min}$ of control compared with the 5 min period from 25 to 30 min after HFS or wash-out of (S)-3,5dihydroxyphenylglycine (DHPG) or as otherwise stated in the text.

Individual mIPSCs were counted and analyzed offline using MiniAnalysis software (Synaptosoft). Each mIPSC event was visually accepted or rejected based upon the rise and decay times after an automatic screening by the software.

Statistical analysis of the data was performed using SigmaStat 3.1 (SPSS). Results are given as means \pm 1 SEM. Statistical comparison of mean values were determined using Student's paired $t$ test for normally distributed data or Wilcoxon signed rank test for nonnormally distributed data. The critical value for statistical significance was set at $p<0.05$ $\left.{ }^{*}\right), p<0.01\left(^{* *}\right)$.

Drugs. All drugs were added to the bath solution at known concentrations. Drugs used were bicuculline (Fluka); 2-diethylamino- $\mathrm{N}$-(2,6dimethylphenyl)acetamide (lidocaine; Alexis); $N$ - $\omega$-nitro-L-arginine methyl ester (L-NAME), CNQX, and GDP- $\beta$ S and strychnine (all Sigma Aldrich); DHPG; 2-methyl-6-(phenylethynyl)pyridine (MPEP), and 2-(4-carboxyphenyl)4,4,5,5-tetramethyl-imidazoline-1-oxyl-3-oxide (cPTIO; all Tocris Bioscience); $(S)-(+)-\alpha$-amino-4-carboxy-2-methylbenzeneacetic acid (LY367385), S-nitroso- $N$-acetyl-DL-penicillamin (SNAP), and D-AP5 (all Ascent Scientific).

Drugs were applied for at least $20 \mathrm{~min}$ before HFS or DHPG application or as otherwise stated in the text. Control drug-free experiments were interleaved with experiments using drug application.

\section{Results}

\section{Conditioning stimulation of small} primary afferent nerve fibers induces LTP at GABAergic synapses

We performed whole-cell patch-clamp recordings from spinal lamina I neurons.

To isolate monosynaptic GABAergic IPSCs, recordings were made in the presence of ionotropic glutamate (CNQX, D-AP5) and glycine (strychnine) receptor antagonists. IPSCs were evoked by focal stimulation in the superficial dorsal horn (Fig. $1 A$ ). Neurons were kept at a holding potential of $0 \mathrm{mV}$ with a cesium-based internal solution. Under these conditions IPSCs appeared as outward currents and were completely blocked by bath application of bicuculline. These IPSCs were thus mediated by $\mathrm{GABA}_{\mathrm{A}}$ receptors (Fig. $1 \mathrm{~B}$ ).

We established a stable baseline of IPSCs evoked by focal stimulation for $5 \mathrm{~min}$. We then applied conditioning high-frequency stimulation to the attached dorsal root via a suction electrode (Fig. 1A). HFS induced LTP of the GABAergic IPSC amplitudes $\left(\mathrm{LTP}_{\mathrm{GABA}}\right)$ in 8 out of 13 lamina I neurons tested (to $148 \pm 9 \%$ of control; $p<0.001$; Fig. $1 C, D)$. We next evaluated the glutamatergic afferent input to the neurons under study. All drugs were washed out for at least $10 \mathrm{~min}$ at the end of the experiment. The neurons were then clamped to a holding potential of $-70 \mathrm{mV}$, 
and synaptic input from attached dorsal root was assessed. Monosynaptic EPSCs were identified as described previously (Dahlhaus et al., 2005). Analysis of the data revealed that all eight neurons in which $\mathrm{LTP}_{\mathrm{GABA}}$ was induced received either monosynaptic A $\delta$-fiber or monosynaptic C-fiber input from attached dorsal roots (Fig. $1 G$ ). The remaining five neurons, in which HFS was ineffective $(88 \pm 11 \%$ of control; Fig. $1 E, F)$, received polysynaptic but no monosynaptic input from the attached dorsal roots in the slice preparation (Fig. $1 H$ ).

\section{$\mathrm{LTP}_{\mathrm{GABA}}$ is mediated by group I} metabotropic glutamate receptors

We next explored the mechanisms that trigger $\mathrm{LTP}_{\mathrm{GABA}}$. During conditioning stimulation, ionotropic glutamate receptors were blocked by specific antagonists applied to the bath solution. We thus hypothesized that group I mGluRs, which are highly expressed in the superficial dorsal horn (Jia et al., 1999), may be activated during HFS and mediate LTP $_{\text {GABA }}$. To test this hypothesis we performed experiments in the presence of $100 \mu \mathrm{M}$ LY367385 and 30 $\mu \mathrm{M}$ MPEP, which are selective antagonists of mGluR subtypes 1 and 5, respectively. Only neurons that received either monosynaptic $\mathrm{A} \delta$-fiber or C-fiber input were used for further analysis. During bath application of the group I mGluR antagonists, induction of $\mathrm{LTP}_{\mathrm{GABA}}$ was abolished in all neurons tested ( $92 \pm 13 \%$ of control; $n=5$; Fig.

$2 A, B)$, indicating that activation of group I mGluRs is necessary for the induction of $\mathrm{LTP}_{\mathrm{GABA}}$. We next tested whether activation of group I mGluRs is also sufficient for the induction of $\mathrm{LTP}_{\mathrm{GABA}}$. Bath application of the selective group I mGluR agonist DHPG $(50 \mu \mathrm{M})$ for 10 min induced a transient enhancement of the IPSC amplitudes followed by a long-lasting potentiation (to $136 \pm 12 \%$ of control; 30 min after wash-out, $n=17, p<0.001$; Fig. $2 C, D$ ). The DHPGinduced $\mathrm{LTP}_{\mathrm{GABA}}$ remained undiminished for the remaining of the recording periods up to $50 \mathrm{~min}$ after wash-out (Fig. 2C). Superficial dorsal horn neurons express high levels of group I mGluRs on their somata and also on the terminals of GABAergic neurons (Jia et al., 1999; Tao et al., 2000). To examine, whether postsynaptic mGluR signaling is involved in DHPG-induced LTP $_{\mathrm{GABA}}$, we added the G-protein inhibitor GDP- $\beta S$ ( $0.5 \mathrm{~mm})$ to the recording pipette solution. Bath application of DHPG induced a transient increase of the IPSC amplitudes, but the long-lasting potentiation was completely blocked (to $85 \pm 12 \%$ of control, 30 min after wash-out of DHPG; $n=6$; Fig. $2 E, F)$. These results demonstrate that DHPG-induced long-lasting potentiation requires activation of postsynaptic G-proteins.

\section{LTP $_{\text {GABA }}$ is expressed presynaptically}

To determine the locus of the expression of $\mathrm{LTP}_{\mathrm{GABA}}$, pairedpulse stimulation experiments were performed. After induction of $\mathrm{LTP}_{\mathrm{GABA}}$ by HFS, the paired-pulse ratio decreased (to $0.75 \pm$ 0.08 of control value; $n=8, p<0.05$; Fig. $3 A$ ). The decrease in $\mathrm{PPR}$ is consistent with a presynaptic expression of $\mathrm{LTP}_{\mathrm{GABA}}$. In
B
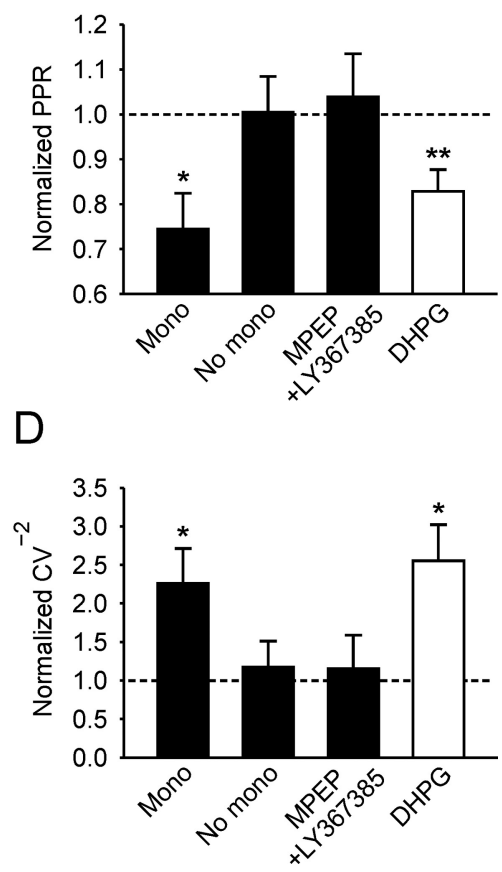

Figure 3. Presynaptic expression of $L T P_{G A B A} \cdot A, H F S$-induced $L T P_{G A B A}$ is accompanied by a decrease in the PPR. Synaptic currents

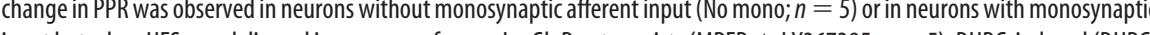
data are plotted in $5 \mathrm{~min}$ blocks against time. Inset: Example of variability of 20 IPSCs $0-5$ min before and 25-30 min after HFS Calibration: 20 ms, 100 pA. D, Summary showing the effects on the $\mathrm{CV}^{-2}$ under various conditions. Labeling is the same as in $\boldsymbol{B}$. All neurons included in $\boldsymbol{A}$ and $\boldsymbol{C}$ received either monosynaptic $A \delta$-fiber or $C$-fiber input from attached dorsal roots.

neurons that did not display $\mathrm{LTP}_{\mathrm{GABA}}$, no significant changes of the PPR were observed ( $p>0.05 ; n=5$; Fig. $3 B)$. In experiments where HFS-induced LTP $_{\mathrm{GABA}}$ was blocked by group I mGluR antagonists, the PPR remained unchanged ( $p>0.05 ; n=5$; Fig. $3 B)$. We next asked whether DHPG-induced $\mathrm{LTP}_{\mathrm{GABA}}$ is also expressed presynaptically. Indeed, DHPG-induced LTP $\mathrm{GABA}_{\mathrm{GA}}$ was associated with a decrease in the PPR (to $0.83 \pm 0.05$ of control value; $n=10 ; p<0.01$; Fig. $3 B$ ). The presynaptic expression of $\mathrm{LTP}_{\mathrm{GABA}}$ was further confirmed by changes in the $\mathrm{CV}^{-2}$, where $\mathrm{CV}$ is the coefficient of variation. $\mathrm{LTP}_{\mathrm{GABA}}$ was accompanied by an increase of the $\mathrm{CV}^{-2}$ (to $2.27 \pm 0.45$ of control value; $n=8$; $p<0.05$; Fig. 3C). Likewise, DHPG-induced $\mathrm{LTP}_{\mathrm{GABA}}$ was also associated with an increase of the $\mathrm{CV}^{-2}$ (to $2.55 \pm 0.47$ of control value; $n=17 ; p<0.05$; Fig. $3 D$ ). No change of the $\mathrm{CV}^{-2}$ was observed, however, in neurons that did not express LTP $_{\mathrm{GABA}}$, either because they had no monosynaptic input from dorsal roots or because group I mGluRs were blocked (Fig. 3D).

To further investigate whether transmitter release is enhanced at GABAergic synapses after conditioning HFS, miniature IPSCs were recorded in presence of lidocaine $(2 \mathrm{~mm})$ to block action potential-dependent effects. These mIPSCs were completely blocked by bicuculline, confirming that they were mediated by $\mathrm{GABA}_{\mathrm{A}}$ receptors $(n=5$, data not shown). A stable baseline of mIPSCs was first recorded for $5 \mathrm{~min}$ as a control, followed by a wash-out period of lidocaine for $15 \mathrm{~min}$. Then HFS was applied to the attached dorsal root and lidocaine was subsequently washed in (Fig. 4A). The frequency of mIPSCs 25-30 min after 
A

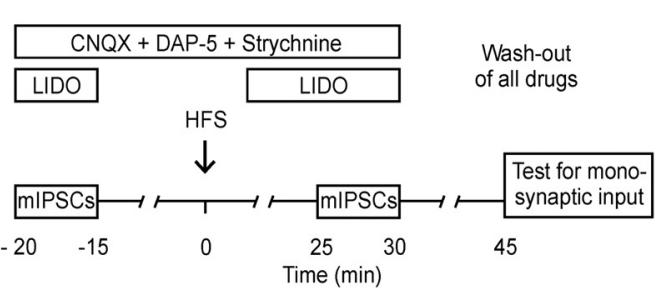

C

25 - 30 min after HFS

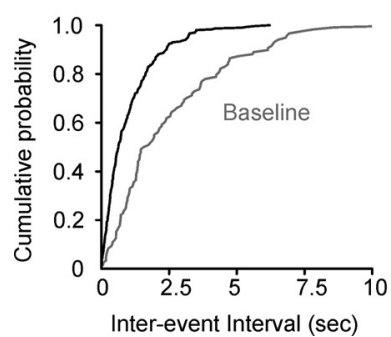

25 - 30 min after HFS

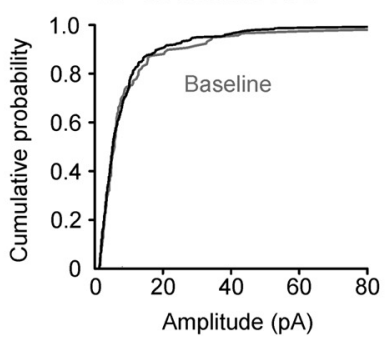

B

Baseline

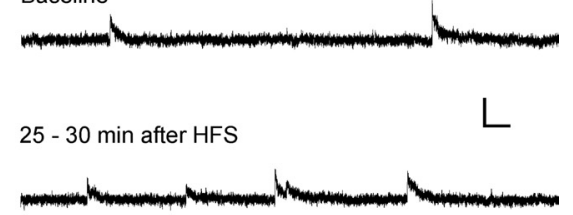

D

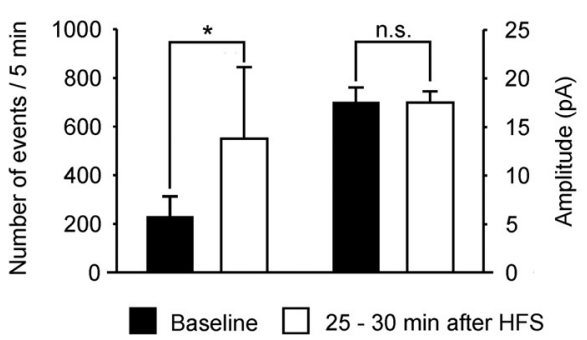

Figure 4. HFS increases the frequency but not the amplitude of mIPSCs in spinal lamina I neurons. $A$, Experimental design for the recording of mIPSCs. LIDO, Lidocaine. $B$, Representative example of mIPSCs recorded from a spinal lamina I neuron that received monosynaptic $A \delta$-fiber input from attached dorsal root under baseline conditions and $25-30 \mathrm{~min}$ after HFS. Calibration: $100 \mathrm{~ms}, 20$ pA. C, The cumulative probability curve of inter-event intervals for mIPSCs from the same neuron as that in $\boldsymbol{A}$ was shifted 25-30 min after HFS compared to baseline, indicating an enhanced transmitter release. In contrast, no change of the cumulative probability curve of amplitudes of mIPSCs was observed. A total of 118 events for baseline and 300 events for $25-30$ min after HFS were plotted. $\boldsymbol{D}$, Summary of the change in frequency and amplitude of mIPSCs from six neurons that received monosynaptic glutamatergic input from primary afferent A $\delta$-fibers or C-fibers.

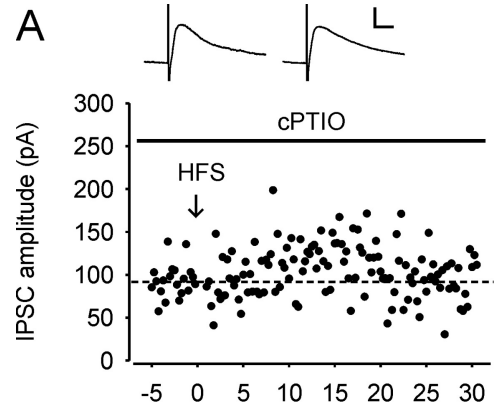

$\mathrm{B}$
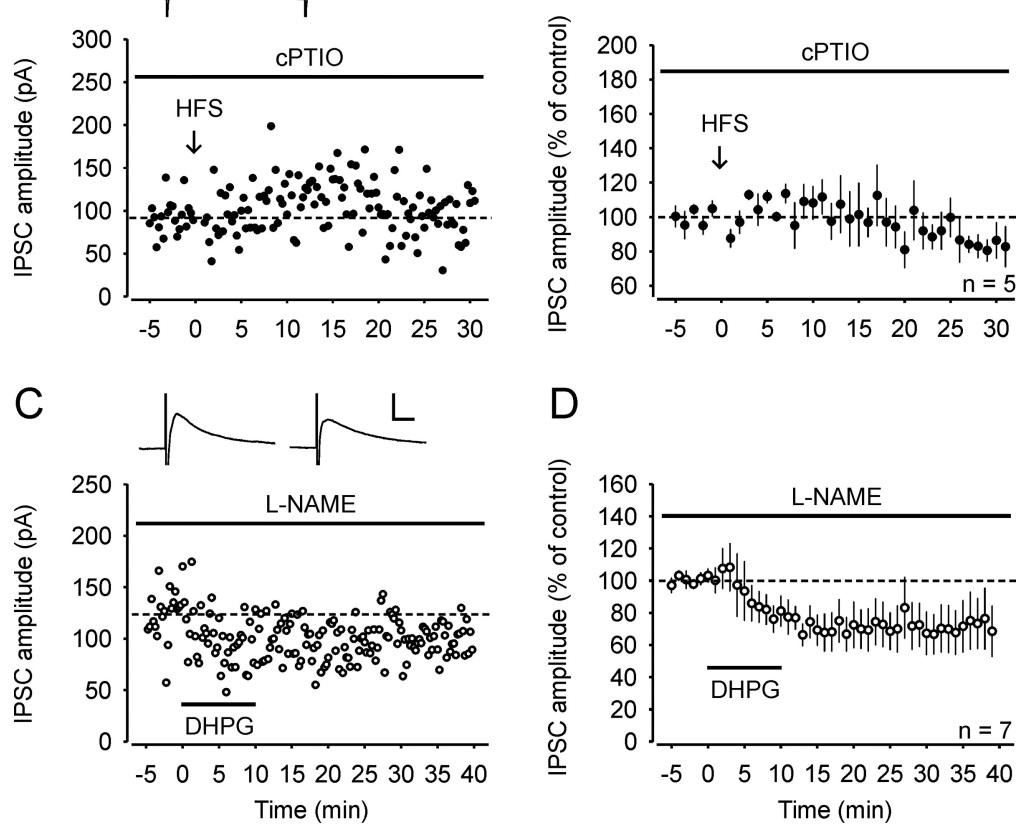

$\mathrm{D}$

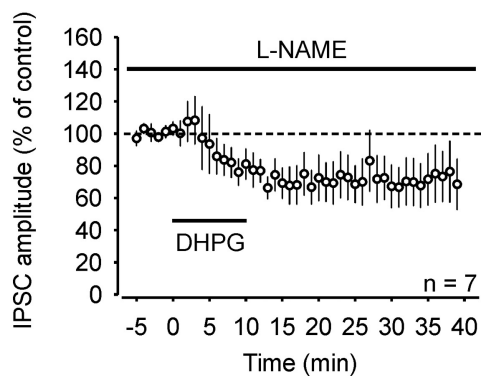

Figure 5. Induction of $\mathrm{LTP}_{\mathrm{GABA}}$ on spinal lamina I neurons requires $\mathrm{NO}$ signaling. $A$, Example of an experiment where HFS was applied in the presence of the NO scavenger CPTIO $(30 \mu \mathrm{M})$. The neuron received monosynaptic C-fiber input. Inset: Average of 20 IPSCS $0-5$ min before and $25-30$ min after conditioning stimulation. $\boldsymbol{B}$, Average of five experiments where HFS was delivered in presence of $\mathrm{PPT} 0$ and failed to trigger $\mathrm{LTP}_{\mathrm{GABA}}$. All neurons received either monosynaptic $\mathrm{A} \delta$-fiber or $\mathrm{C}$-fiber input from attached dorsal roots. C, Example of an experiment where DHPG was bath applied in presence of the NOS inhibitor L-NAME (100 $\mu \mathrm{M})$. Wash-in of the group I mGluR agonist induced a long-lasting depression instead of a potentiation of the IPSC amplitudes. Inset: Average of 20 IPSCs $0-5$ min before bath application of DHPG and $25-30 \mathrm{~min}$ after wash-out of the inducing agonist. $D$, Average of seven experiments where DHPG was applied in presence of L-NAME. Calibration: $10 \mathrm{~ms}, 50 \mathrm{pA}(\boldsymbol{A}) ; 10 \mathrm{~ms}, 100 \mathrm{pA}(\boldsymbol{C})$.

HFS was significantly increased in neurons that received monosynaptic input from the attached dorsal root (from $233 \pm 82$ to $565 \pm 289$ events in 5 min; $n=6 ; p<0.05$; Fig. $4 B, C, D)$. The amplitude of mIPSCs was not altered after conditioning HFS (baseline $17 \pm 1 \mathrm{pA}$ vs $17 \pm 1 \mathrm{pA}$ at $25-30$ min after HFS; $p>0.05$; Fig. 4 B,C,D). Neither the frequency nor the amplitude of mIPSCs was affected in three neurons that did not receive monosynaptic input from attached dorsal roots (data not shown).

Collectively, the data indicate that $\mathrm{LTP}_{\mathrm{GABA}}$ is due to a persistent increase in the release of GABA. The postsynaptic induction and the presynaptic expression of $\mathrm{LTP}_{\mathrm{GABA}}$ suggest that a retrograde messenger is involved.

\section{Nitric oxide signaling mediates}

LTP $_{\text {GABA }}$

$\mathrm{NO}$ is a potential retrograde messenger in the superficial dorsal horn where NO synthase (NOS) is expressed (Saito et al., 1994). We thus tested whether NO is required for the induction of $\mathrm{LTP}_{\mathrm{GABA}}$. Bath application of the NO scavenger CPTIO $(30 \mu \mathrm{M})$ completely prevented the induction of $\mathrm{LTP}_{\mathrm{GABA}}$. Compared to baseline, IPSC amplitudes 25-30 min after HFS were significantly depressed (to $83 \pm 8.0 \%$ of control; $n=5$; $p<0.01$; all neurons received either monosynaptic $A \delta$-fiber or monosynaptic C-fiber input; Fig. 5A,B). cPTIO is a membrane-impermeant scavenger of NO, suggesting that NO must diffuse through the extracellular space to exert its action on GABAergic terminals. We then tested whether $\mathrm{NO}$ is also required for

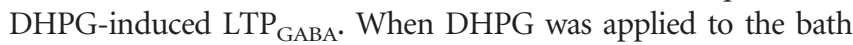
solution in the presence of the NOS inhibitor L-NAME $(100 \mu \mathrm{M})$, $\mathrm{LTP}_{\mathrm{GABA}}$ was not only fully blocked but converted into a long-term 
depression (LTD) of the IPSC amplitudes (to $73 \pm 17 \%$ of control; $n=7 ; p<0.01$; Fig. $5 C, D)$.

Next we tested whether NO is sufficient to enhance GABA release. Bath application of the NO donor SNAP (200 $\mu \mathrm{M})$ resulted in an increase of the IPSC amplitudes (to $166 \pm 17 \%$ of control; $n=$ $5 ; p<0.001 ; 25-30$ min after wash-in; Fig. $6 A, B)$. The SNAP-induced potentiation was accompanied by a decrease of the PPR (to $0.80 \pm 0.03$ of the control value; $n=5$; $p<0.01$; Fig. 6C) and an increase of the $\mathrm{CV}^{-2}$ (to $3.46 \pm 0.52$ of the control value; $n=5 ; p<0.05$; Fig. $6 D$ ), consistent with an increase in the release probability of GABA.

We also asked whether SNAP-induced potentiation occludes $\mathrm{LTP}_{\mathrm{GABA}}$. When slices were pretreated with SNAP for at least $30 \mathrm{~min}$ before the whole-cell configuration was achieved, HFS failed to induce $\mathrm{LTP}_{\mathrm{GABA}}$. Compared to control, the amplitudes of IPSCs 25-30 min after HFS were significantly depressed (to $83 \pm 14.0 \%$ of control; $n=5$; $p<0.05$; all neurons received either monosynaptic $\mathrm{A} \delta$ - or monosynaptic C-fiber input; Fig. $6 E, F)$. This suggests that SNAP-induced potentiation shares signaling pathways with HFSinduced potentiation at spinal GABAergic synapses and further supports the belief that $\mathrm{NO}$ signaling is required for $\mathrm{LTP}_{\mathrm{GABA}}$.

\section{Discussion}

The present study revealed a novel form of synaptic plasticity in the spinal dorsal horn that was induced by conditioning stimulation of primary afferent $A \delta$ - or C-fibers. The heterosynaptic LTP at GABAergic synapses, which was induced postsynaptically by group I mGluRs, expressed presynaptically and involved $\mathrm{NO}$ as a retrograde messenger (Fig. 7). This is the first report to demonstrate the following: (1) activity-dependent plasticity at inhibitory synapses in the spinal cord; and (2) a heterosynaptic form of LTP in spinal dorsal horn neurons.

\section{$\mathrm{LTP}_{\mathrm{GABA}}$ in the superficial dorsal horn is heterosynaptic in nature}

We applied the conditioning HFS to the dorsal root while spinal ionotropic glutamate receptors were blocked by selective antagonists in the bath solution. Thus, glutamate released from the terminals of primary afferent nerve fibers by the conditioning stimulation could not excite any postsynaptic neuron. Consequently, all disynaptic and polysynaptic pathways were blocked. Glutamate required for the activation of mGluRs could then derive from three sources only: (1) directly from monosynaptic primary afferent input converging onto the neurons under study; (2) from primary afferents contacting other spinal neurons via spillover; or (3) from ambient levels of glutamate, e.g., released from glial cells. The fact that $\mathrm{LTP}_{\mathrm{GABA}}$ could be triggered exclu-

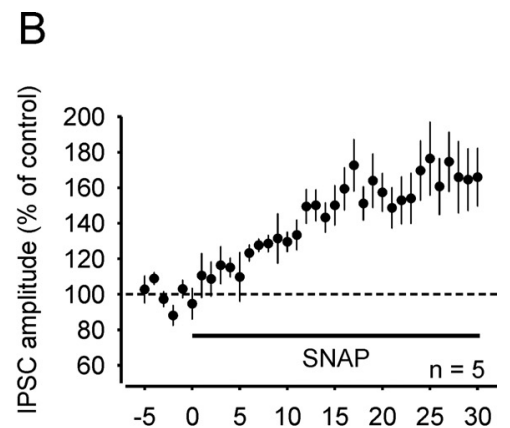

D
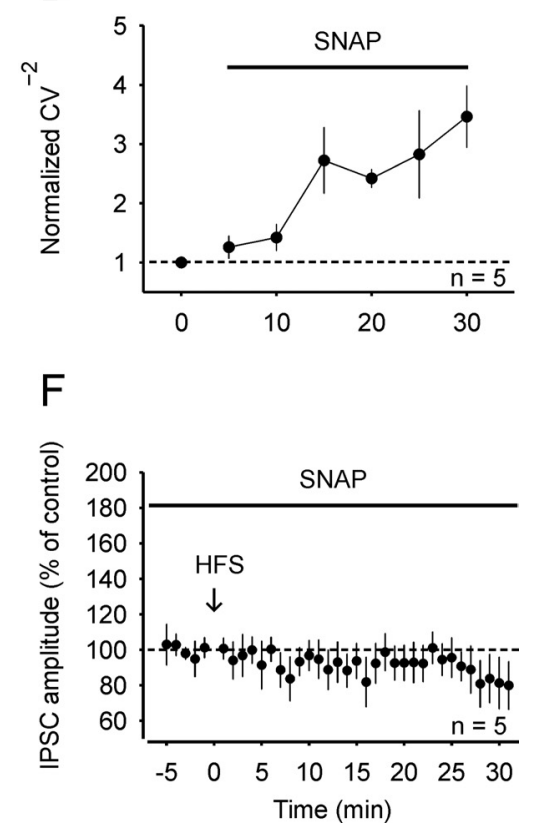

Figure 6. The NO donor SNAP enhances GABAergic IPSCs in spinal lamina I neurons and occludes HFS-induced LTP ${ }_{\text {GABA}}$. $\boldsymbol{A}_{\text {, }}$ Example of an experiment where the NO donor SNAP $(200 \mu \mathrm{m})$ was applied to the bath solution and potentiated the IPSC 列 slices were pretreated with SNAP. All neurons received monosynaptic glutamatergic input from primary afferent $A \delta$-fibers or C-fibers. Calibration: $10 \mathrm{~ms}, 100 \mathrm{pA}(\boldsymbol{A}) ; 10 \mathrm{~ms}, 50 \mathrm{pA}(\boldsymbol{E})$.

sively in those neurons that received monosynaptic input from $\mathrm{A} \delta$-fibers or $\mathrm{C}$-fibers suggests that any spillover of glutamate from primary afferents or ambient glutamate was not sufficient for the induction of $\mathrm{LTP}_{\mathrm{GABA}}$. The most direct explanation of the present data is that glutamate was released from primary afferents and activated postsynaptic metabotropic glutamate receptors on spinal lamina I neurons, which then triggered $\mathrm{LTP}_{\mathrm{GABA}}$ by a heterosynaptic mechanism (Fig. 7).

$\mathrm{LTP}_{\mathrm{GABA}}$ in spinal dorsal horn as described here shares some fundamental features with previously described $\mathrm{LTP}_{\mathrm{GABA}}$ at synapses in the ventral tegmental area (Nugent et al., 2007). Both forms of synaptic plasticity are triggered by high-frequency conditioning stimulation of glutamatergic synapses; they are heterosynaptic in nature, expressed presynaptically, and involve NO as a retrograde messenger. Both forms of $\mathrm{LTP}_{\mathrm{GABA}}$ also differ in important aspects. While $\mathrm{LTP}_{\mathrm{GABA}}$ in the ventral tegmental area requires activation of NMDA receptors (Nugent et al., 2007), 


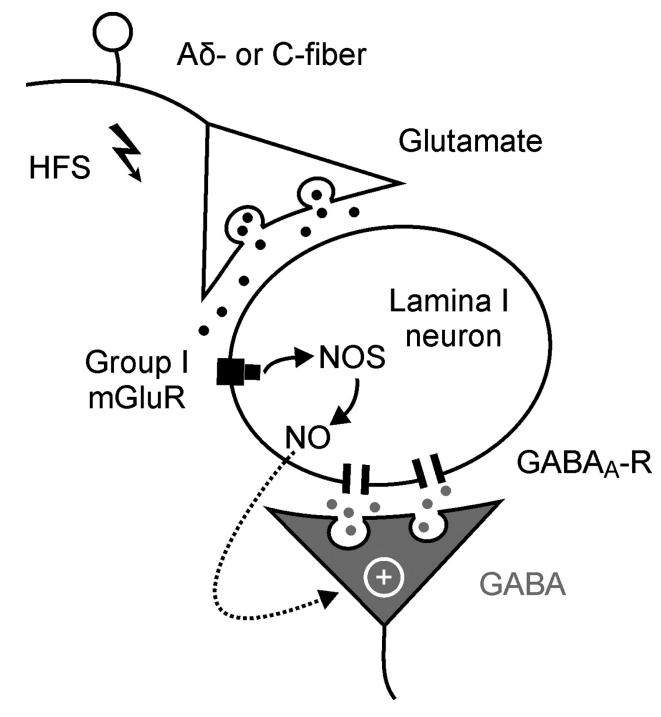

Figure 7. Schematic diagram of heterosynaptic LTP at GABAergic synapses with spinal lamina I neurons that receive monosynaptic glutamatergic input from primary afferent $A \delta$-fibers or C-fibers. Glutamate is released upon high-frequency conditioning stimulation and activates group I metabotropic glutamate receptors on spinal lamina I neurons. Nitric oxide is released via a postsynaptic, G-protein-dependent mechanism and enhances transmitter release at GABAergic synapses converging onto the same neuron.

$\mathrm{LTP}_{\mathrm{GABA}}$ in the spinal dorsal horn was independent of NMDA receptors but instead required activation of group I mGluRs.

GABA and glycine can be co-released from the same synaptic vesicle at spinal inhibitory synapses (Jonas et al., 1998). If glycine and GABA were co-released from the same vesicles in the present study, presynaptically expressed LTP should then also apply to glycinergic transmission. Co-release of glycine and GABA has been shown to occur mainly in the immature spinal cord. Mixed $\mathrm{GABA}_{\mathrm{A}} /$ glycine receptor-mediated postsynaptic events become less frequent during maturation and disappear in spinal dorsal horn neurons by postnatal day 23 (Keller et al., 2001). Significant co-release may thus not to be expected in 25- to 35-d-old rats used in the present study. Furthermore, GABAergic and glycinergic spinal synapses are regulated differently under physiological conditions (Choi et al., 2009; Yowtak et al., 2011) and by peripheral nerve injury (Moore et al., 2002; Coull et al., 2003), suggesting a transmitter-specific regulation of synaptic release. It will be interesting to explore in future experiments if and how transmission at spinal glycinergic synapses might also be regulated by a heterosynaptic mechanism.

\section{Group I mGluR activation is necessary and sufficient for presynaptically expressed $\mathrm{LTP}_{\mathrm{GABA}}$}

In the superficial spinal dorsal horn group I mGluRs are expressed on the somata of spinal neurons and on the terminals of GABAergic neurons (Jia et al., 1999; Tao et al., 2000). Here, induction of LTP $_{\text {GABA }}$ by HFS was prevented when mGluR1 and mGluR5 receptors were blocked. Activation of group I mGluRs by bath application of DHPG induced LTP $_{\mathrm{GABA}}$, and this required postsynaptic G-protein coupling. These results demonstrate that activation of postsynaptic G-protein-coupled receptors is not only necessary but also sufficient for the induction of $\mathrm{LTP}_{\mathrm{GABA}}$ in spinal lamina I neurons.

Activation of group I mGluRs leads to either LTP (Anwyl, 2009) or LTD (Lüscher and Huber, 2010) at excitatory synapses in various areas of the brain. The expression of synaptic plasticity can be presynaptic or postsynaptic, depending upon the type of synapse under study. At GABAergic synapses, activation of group I mGluRs mainly leads to presynaptically expressed LTD (Chevaleyre and Castillo, 2003; Heifets et al., 2008; Pan et al., 2008). In the only previous study where activation of group I mGluRs was necessary for the induction of LTP at GABAergic synapses on CA1 pyramidal cells, the expression was postsynaptic (Patenaude et al., 2003). Interestingly, we now provide evidence that LTP at GABAergic synapses with spinal lamina I neurons is expressed presynaptically. LTP $_{\text {GABA }}$ induced either by conditioning HFS of primary afferents or by bath application of DHPG was associated with a decrease of the PPR and an increase in the $\mathrm{CV}^{-2}$. Additionally, the frequency but not the amplitude of mIPSCs was increased by conditioning HFS. Together, these findings are consistent with a presynaptic expression of $\mathrm{LTP}_{\mathrm{GABA}}$. Our results thus revealed a previously unrecognized presynaptic regulation of GABAergic transmission triggered by activation of postsynaptic group I mGluRs.

\section{Nitric oxide enhances GABA release in the superficial spinal dorsal horn}

$\mathrm{NO}$ is a prime candidate for a retrograde messenger in the spinal dorsal horn (Meller and Gebhart, 1993). Its functions for nociception are, however, still not fully understood. Inhibition of NO synthesis in the spinal cord reduces inflammatory and neuropathic pain, suggesting an overall pronociceptive effect of $\mathrm{NO}$ (Meller et al., 1992; Malmberg and Yaksh1993). Spinal application of NO donors or cGMP analogs revealed conflicting results as pronociceptive and antinociceptive effects have been observed (Sousa and Prado, 2001; Tegeder et al., 2002; Schmidtko et al., 2008). The effect of NO on the spontaneous activity of spinal neurons varies with respect to the lamina location. In spinal laminae I and II, but not in lamina X, NO reduces the frequency of action potential discharges in a substantial fraction of neurons (Pehl and Schmid, 1997). Here we report that bath application of a NO donor enhanced GABAergic transmission at spinal lamina I neurons and that NO signaling was necessary for the induction of $\mathrm{LTP}_{\mathrm{GABA}}$. The NO-sensitive guanylate cyclase is found in presynaptic terminals of spinal GABAergic synapses (Ding and Weinberg, 2006). Activation of presynaptic guanylate cyclase has been shown to control NO-dependent LTP not only at GABAergic synapses but also at glutamatergic synapses (Zhuo et al., 1994; Nugent et al., 2007). In fact, we have shown previously that NO signaling mediates one type of LTP at glutamatergic synapses between C-fibers and spinal lamina I projection neurons. NO was required for LTP induced by conditioning low-frequency stimulation (at $2 \mathrm{~Hz}$ ), but not for LTP induced by HFS (100 Hz) (Ikeda et al., 2006). The latter conditioning stimulus was also used in the present study. The signaling pathways of NO-dependent, presynaptically expressed LTP at GABAergic and glutamatergic synapses may thus overlap, while the induction protocols are different. Our results further substantiate the emerging role of NO for plasticity at inhibitory synapses (Makara et al., 2007; Nugent et al., 2007; Niehaus et al., 2010).

\section{Potential functional consequences of $\mathrm{LTP}_{\mathrm{GABA}}$ in nociceptive pathways}

Previous work indicates that most neurons located in lamina I of the spinal cord, being either excitatory or inhibitory, receive monosynaptic input from either A $\delta$-fibers and/or C-fibers (Yoshimura and Jessell, 1990; Dahlhaus et al., 2005; Yasaka et al., 2007; Pinto et al., 2010), and many also express group I mGluRs (Alvarez et al., 2000). In the present study, we recorded from unidentified lamina I neurons and showed that $\mathrm{LTP}_{\mathrm{GABA}}$ could 
be induced in all neurons that received monosynaptic input from small primary afferents. In contrast, the same conditioning stimulation triggers LTP only at a subset of glutamatergic C-fiber synapses of lamina I neurons projecting to the parabrachial area (Ikeda et al., 2006). Thus, an enhancement of inhibition due to LTP $_{\text {GABA }}$ at many GABAergic synapses at lamina I neurons and parallel LTP at synapses of selected C-fibers with spinal projection neurons leads to an enhanced contrast between the afferent signal and the background "noise." Thereby, heterosynaptic $\mathrm{LTP}_{\mathrm{GABA}}$ in lamina I may function as a filter for improving novelty detection and for enhancing the signal-to-noise ratio in spinal nociceptive pathways.

Inhibitory systems in spinal dorsal horn may serve at least five principle functions (Sandkühler, 2009, 2012) that would all be strengthened by $\mathrm{LTP}_{\mathrm{GABA}}$. (1) Attenuation of nociceptive responses to an appropriate level to prevent hyperalgesia. (2) Muting of nociceptive neurons in the absence of any sensory stimulus to prevent spontaneous pain. (3) Functionally separating pathways for different sensory modalities. This is required for avoiding any crosstalk between low threshold sensory input such as touch and the nociceptive system. A cross-talk would otherwise lead to touch-evoked pain (allodynia). (4) Limiting the spread of excitation to somatotopically adequate areas of the spinal dorsal horn. A failure of this function of inhibitory spinal systems would lead to spreading sensations, including secondary hyperalgesia. (5) The prevention of LTP induction at synapses of nociceptive afferent nerve fibers. LTP $_{\text {GABA }}$ likely has a considerable impact on the inducibility of synaptic plasticity in the nociceptive system of the spinal dorsal horn. Enhanced GABAergic inhibition blocks both the induction and the maintenance of LTP of C-fiberevoked field potentials in spinal dorsal horn in vivo (Hu et al., 2006). When inhibition via $\mathrm{GABA}_{\mathrm{A}}$ receptors is fully blocked, conditioning stimulation, which normally induces LTD, now leads to LTP induction (Miletic and Miletic, 2001). Likewise, blocking spinal inhibition during conditioning stimulation of dorsal root afferents converts depression of long-lasting excitatory optical responses in the superficial dorsal horn to facilitation (Ikeda et al., 2000). A globally enhanced GABAergic inhibition due to $\mathrm{LTP}_{\mathrm{GABA}}$ is therefore expected to hinder any subsequent LTP induction at glutamatergic synapses converging onto the same postsynaptic dorsal horn neurons.

In summary, the present study identified a novel mechanism through which spinal nociception can be modulated in an activity-dependent manner. It will be interesting to explore whether this form of synaptic plasticity is modified under inflammatory or neuropathic pain conditions.

\section{References}

Alvarez FJ, Villalba RM, Carr PA, Grandes P, Somohano PM (2000) Differential distribution of metabotropic glutamate receptors $1 \mathrm{a}, 1 \mathrm{~b}$, and 5 in the rat spinal cord. J Comp Neurol 422:464-487.

Anwyl R (2009) Metabotropic glutamate receptor-dependent long-term potentiation. Neuropharmacology 56:735-740.

Baba H, Ji RR, Kohno T, Moore KA, Ataka T, Wakai A, Okamoto M, Woolf CJ (2003) Removal of GABAergic inhibition facilitates polysynaptic A fibermediated excitatory transmission to the superficial spinal dorsal horn. Mol Cell Neurosci 24:818-830.

Chen YJ, Zhang M, Yin DM, Wen L, Ting A, Wang P, Lu YS, Zhu XH, Li SJ, Wu CY, Wang XM, Lai C, Xiong WC, Mei L, Gao TM (2010) ErbB4 in parvalbumin-positive interneurons is critical for neuregulin 1 regulation of long-term potentiation. Proc Natl Acad Sci U S A 107:21818-21823.

Chevaleyre V, Castillo PE (2003) Heterosynaptic LTD of hippocampal GABAergic synapses: a novel role of endocannabinoids in regulating excitability. Neuron 38:461-472.

Choi IS, Nakamura M, Cho JH, Park HM, Kim SJ, Kim J, Lee JJ, Choi BJ, Jang
IS (2009) Cyclic AMP-mediated long-term facilitation of glycinergic transmission in developing spinal dorsal horn neurons. J Neurochem 110:1695-1706.

Coull JA, Boudreau D, Bachand K, Prescott SA, Nault F, Sík A, De Koninck P, De Koninck Y (2003) Trans-synaptic shift in anion gradient in spinal lamina I neurons as a mechanism of neuropathic pain. Nature 424:938-942.

Dahlhaus A, Ruscheweyh R, Sandkühler J (2005) Synaptic input of rat spinal lamina I projection and unidentified neurons in vitro. J Physiol 566:355-368.

Ding JD, Weinberg RJ (2006) Localization of soluble guanylyl cyclase in the superficial dorsal horn. J Comp Neurol 495:668-678.

Dodt H, Eder M, Frick A, Zieglgänsberger W (1999) Precisely localized LTD in the neocortex revealed by infrared-guided laser stimulation. Science 286:110-113.

Drdla R, Gassner M, Gingl E, Sandkühler J (2009) Induction of synaptic long-term potentiation after opioid withdrawal. Science 325:207-210.

Heifets BD, Chevaleyre V, Castillo PE (2008) Interneuron activity controls endocannabinoid-mediated presynaptic plasticity through calcineurin. Proc Natl Acad Sci U S A 105:10250-10255.

Hu XD, Ge YX, Hu NW, Zhang HM, Zhou LJ, Zhang T, Li WM, Han YF, Liu XG (2006) Diazepam inhibits the induction and maintenance of LTP of C-fiber evoked field potentials in spinal dorsal horn of rats. Neuropharmacology 50:238-244.

Ikeda H, Asai T, Murase K (2000) Robust changes of afferent-induced excitation in the rat spinal dorsal horn after conditioning high-frequency stimulation. J Neurophysiol 83:2412-2420.

Ikeda H, Heinke B, Ruscheweyh R, Sandkühler J (2003) Synaptic plasticity in spinal lamina I projection neurons that mediate hyperalgesia. Science 299:1237-1240.

Ikeda H, Stark J, Fischer H, Wagner M, Drdla R, Jäger T, Sandkühler J (2006) Synaptic amplifier of inflammatory pain in the spinal dorsal horn. Science 312:1659-1662.

Ishikawa T, Marsala M, Sakabe T, Yaksh TL (2000) Characterization of spinal amino acid release and touch-evoked allodynia produced by spinal glycine or $\mathrm{GABA}_{\mathrm{A}}$ receptor antagonist. Neuroscience 95:781-786.

Jia H, Rustioni A, ValtschanoffJG (1999) Metabotropic glutamate receptors in superficial laminae of the rat dorsal horn. J Comp Neurol 410:627-642.

Jonas P, Bischofberger J, Sandkühler J (1998) Corelease of two fast neurotransmitters at a central synapse. Science 281:419-424.

Keller AF, Coull JAM, Chéry N, Poisbeau P, De Koninck Y (2001) Regionspecific developmental specialization of GABA-glycine cosynapses in laminas I-II of the rat spinal dorsal horn. J Neurosci 21:7871-7880.

Klein T, Magerl W, Hopf HC, Sandkühler J, Treede RD (2004) Perceptual correlates of nociceptive long-term potentiation and long-term depression in humans. J Neurosci 24:964-971.

Lüscher C, Huber KM (2010) Group 1 mGluR-dependent synaptic longterm depression: mechanisms and implications for circuitry and disease. Neuron 65:445-459.

Makara JK, Katona I, Nyíri G, Németh B, Ledent C, Watanabe M, de Vente J, Freund TF, Hájos N (2007) Involvement of nitric oxide in depolarization-induced suppression of inhibition in hippocampal pyramidal cells during activation of cholinergic receptors. J Neurosci 27:10211-10222.

Malan TP, Mata HP, Porreca F (2002) Spinal GABA $A$ and $G_{A B A}$ receptor pharmacology in a rat model of neuropathic pain. Anesthesiology 96:1161-1167.

Malmberg AB, Yaksh TL (1993) Spinal nitric oxide synthesis inhibition blocks NMDA-induced thermal hyperalgesia and produces antinociception in the formalin test in rats. Pain 54:291-300.

Meller ST, Gebhart GF (1993) Nitric oxide (NO) and nociceptive processing in the spinal cord. Pain 52:127-136.

Meller ST, Pechman PS, Gebhart GF, Maves TJ (1992) Nitric oxide mediates the thermal hyperalgesia produced in a model of neuropathic pain in the rat. Neuroscience 50:7-10.

Miletic G, Miletic V (2001) Contribution of GABA-A receptors to metaplasticity in the spinal dorsal horn. Pain 90:157-162.

Moore KA, Kohno T, Karchewski LA, Scholz J, Baba H, Woolf CJ (2002) Partial peripheral nerve injury promotes a selective loss of GABAergic inhibition in the superficial dorsal horn of the spinal cord. J Neurosci 22:6724-6731.

Niehaus JL, Murali M, Kauer JA (2010) Drugs of abuse and stress impair 
LTP at inhibitory synapses in the ventral tegmental area. Eur J Neurosci 32:108-117.

Nugent FS, Penick EC, Kauer JA (2007) Opioids block long-term potentiation of inhibitory synapses. Nature 446:1086-1090.

Pan B, Hillard CJ, Liu QS (2008) $D_{2}$ dopamine receptor activation facilitates endocannabinoid-mediated long-term synaptic depression of GABAergic synaptic transmission in midbrain dopamine neurons via cAMP-protein kinase A signaling. J Neurosci 28:14018-14030.

Patenaude C, Chapman CA, Bertrand S, Congar P, Lacaille JC (2003) $\mathrm{GABA}_{\mathrm{B}}$ receptor- and metabotropic glutamate receptor-dependent cooperative long-term potentiation of rat hippocampal $\mathrm{GABA}_{\mathrm{A}}$ synaptic transmission. J Physiol 553:155-167.

Pehl U, Schmid HA (1997) Electrophysiological responses of neurons in the rat spinal cord to nitric oxide. Neuroscience 77:563-573.

Pinto V, Szûcs P, Lima D, Safronov BV (2010) Multisegmental A $\delta$ - and C-fiber input to neurons in lamina I and the lateral spinal nucleus. J Neurosci 30:2384-2395.

Poisbeau P, Patte-Mensah C, Keller AF, Barrot M, Breton JD, Luis-Delgado OE, Freund-Mercier MJ, Mensah-Nyagan AG, Schlichter R (2005) Inflammatory pain upregulates spinal inhibition via endogenous neurosteroid production. J Neurosci 25:11768-11776.

Randić M, Jiang MC, Cerne R (1993) Long-term potentiation and longterm depression of primary afferent neurotransmission in the rat spinal cord. J Neurosci 13:5228-5241.

Saito S, Kidd GJ, Trapp BD, Dawson TM, Bredt DS, Wilson DA, Traystman RJ, Snyder SH, Hanley DF (1994) Rat spinal cord neurons contain nitric oxide synthase. Neuroscience 59:447-456.

Sandkühler J (2009) Models and mechanisms of hyperalgesia and allodynia. Physiol Rev 89:707-758.

Sandkühler J (2012) Spinal plasticity and pain. In: Wall and Melzack's textbook of pain, Ed 6 (Koltzenburg M, McMahon SB, eds). Philadelphia: Elsevier Churchill Livingstone. In press.

Schmidtko A, Gao W, Sausbier M, Rauhmeier I, Sausbier U, Niederberger E, Scholich K, Huber A, Neuhuber W, Allescher HD, Hofmann F, Tegeder I, Ruth P, Geisslinger G (2008) Cysteine-rich protein 2, a novel downstream effector of cGMP/cGMP-dependent protein kinase I-mediated persistent inflammatory pain. J Neurosci 28:1320-1330.

Schoffnegger D, Ruscheweyh R, Sandkühler J (2008) Spread of excitation across modality borders in spinal dorsal horn of neuropathic rats. Pain 135:300-310.
Seagrove LC, Suzuki R, Dickenson AH (2004) Electrophysiological characterisations of rat lamina I dorsal horn neurones and the involvement of excitatory amino acid receptors. Pain 108:76-87.

Sousa AM, Prado WA (2001) The dual effect of a nitric oxide donor in nociception. Brain Res 897:9-19.

Tao YX, Li YQ, Zhao ZQ, Johns RA (2000) Synaptic relationship of the neurons containing a metabotropic glutamate receptor, mGluR5, with nociceptive primary afferent and GABAergic terminals in rat spinal superficial laminae. Brain Res 875:138-143.

Tegeder I, Schmidtko A, Niederberger E, Ruth P, Geisslinger G (2002) Dual effects of spinally delivered 8-bromo-cyclic guanosine mono-phosphate (8-bromo-cGMP) in formalin-induced nociception in rats. Neurosci Lett 332:146-150.

Todd AJ (2010) Neuronal circuitry for pain processing in the dorsal horn. Nat Rev Neurosci 11:823-836.

Torsney C, MacDermott AB (2006) Disinhibition opens the gate to pathological pain signaling in superficial neurokinin 1 receptor-expressing neurons in rat spinal cord. J Neurosci 26:1833-1843.

Yaksh TL (1989) Behavioral and autonomic correlates of the tactile evoked allodynia produced by spinal glycine inhibition: effects of modulatory receptor systems and excitatory amino acid antagonists. Pain 37:111-123.

Yasaka T, Kato G, Furue H, Rashid MH, Sonohata M, Tamae A, Murata Y, Masuko S, Yoshimura M (2007) Cell-type-specific excitatory and inhibitory circuits involving primary afferents in the substantia gelatinosa of the rat spinal dorsal horn in vitro. J Physiol 581:603-618.

Yoshimura M, Jessell T (1990) Amino acid-mediated EPSPs at primary afferent synapses with substantia gelatinosa neurones in the rat spinal cord. J Physiol 430:315-335.

Yoshimura M, Nishi S (1995) Primary afferent-evoked glycine- and GABAmediated IPSPs in substantia gelatinosa neurones in the rat spinal cord in vitro. J Physiol 482:29-38.

Yowtak J, Lee KY, Kim HY, Wang J, Kim HK, Chung K, Chung JM (2011) Reactive oxygen species contribute to neuropathic pain by reducing spinal GABA release. Pain 152:844-852.

Zhang XC, Zhang Y-Q, Zhao ZQ (2005) Involvement of nitric oxide in long-term potentiation of spinal nociceptive responses in rats. Neuroreport 16:1197-1201.

Zhuo M, Hu Y, Schultz C, Kandel ER, Hawkins RD (1994) Role of guanylyl cyclase and cGMP-dependent protein kinase in long-term potentiation. Nature 368:635-639. 